Velasco Caballero, Sergio.

Investigador, Universidad Politécnica de Valencia, Depto. Escultura.

\title{
Bienvenidos al aburrimiento. Introducción a conciencia.
}

\author{
TIPO DE TRABAJO
}

Póster.

PALABRAS CLAVE

Aburrimiento, conciencia, juicio, creatividad.

KEY WORDS

Boredom, consciousness, judgement, creativity.

\section{RESUMEN}

Introducción a los procesos conscientes que sustentan la noción de aburrimiento como emoción limitante de la creatividad, y por extensión, de la experiencia artística.

Al desvelar su naturaleza de juicio separatista frente al mundo, la interpretación occidental del aburrimiento pasa tímidamente de estigmatizarlo, a valorarlo como un efecto creativo en sí mismo. Esto se debe a la consideración del pensamiento inocente como base para la toma de consciencia de la creatividad, que puede proyectarse en forma de aburrimiento.

\section{ABSTRACT}

We introduce to conscious processes that support the notion of boredom as limiting emotion of creativity and, by extension, of the artistic experience.

By revealing his separatist nature of judgment before the world, the western interpretation of stigmatic boredom passes to regard it shyly as a creative effect. This is due to the use of innocent thinking that is the basis for taking consciousness of our creativity, which can be projected finally like boredom.

\section{CONTENIDO}

Según el análisis fenomenológico del filósofo Rafael Echeverría "el aburrimiento no es algo que pertenezca al mundo (como sucede con las afirmaciones) sino que se trata de un rasgo que es propio de un determinado observador del mundo. No existen, de por si, hechos o eventos aburridos. Sólo existen observadores que ante determinados hechos o eventos, se aburren. El aburrimiento reside en ellos, no en su mundo." ${ }^{1}$ Por esto, generalmente asociado a la separación entre el yo y el mundo, el aburrimiento es provocado por un juicio del pensamiento, que proyecta su interpretación personal sobre lo experimentado, que a su vez nos devuelve este mismo aburrimiento, como un reflejo de nuestro estado de conciencia. La prueba de esto es que no todo el mundo se aburre con lo mismo, ni de la misma forma.

En el aburrimiento se bloquea la subjetividad, evitando la implicación creativa e instaurando la creencia de que el mundo tiene la capacidad de aburrir. Su limitada percepción proyecta sobre lo otro la etiqueta de "aburrido", desvelándose incapaz de asumir la responsabilidad o la culpabilidad que se siente frente al rechazo voluntario del mundo. Teniendo esto en cuenta, vemos que su

${ }^{1}$ ECHEVERRÍA, R., Por la senda del pensar ontológico, Granica, Buenos Aires, 2007, p.187. 
estudio, tan implicado en el fracaso de los procesos creativos, nos dirige a sus mecanismos de percepción. Podríamos decir entonces que el aburrimiento es un estado de la conciencia, causado por prejuicios de carencia creativa y expresado en su peculiar sentimiento. Estos pensamientos han sido tradicionalmente juicios de valor, transmitidos culturalmente como una falta de interés que ignora el potencial creativo del observador, que queda abandonado a sus propias inercias y automatismos. Por lo tanto, y por más que pueda pesar, el aburrimiento es producto de nuestra capacidad creativa. En él somos partícipes y creadores de realidades ("aburridas"). Bien sea desde una predisposición mental para experimentarlo, o desde los modos de relación con el mundo. Su provecho depende de la conciencia que tomemos.

Esto mismo pareció notar François de La Rochefoucauld cuando cuestionó irónicamente su visión estigmatizada: "Perdonamos con frecuencia a quienes nos aburren, pero no podemos perdonar a aquellos a quienes aburrimos." ${ }^{2}$ En la ilusión del aburrimiento, donde nos vemos perjudicados, el perdón a "quienes nos aburren" reconoce y sustenta dicha separación. Sin embargo, el perdón a "quienes aburrimos" contemplaría la ignorancia de éstos como creadores de su propio aburrimiento, permitiendo la disolución del juicio que lo causa. De modo que la experiencia aburrida no es cualidad de la materia o sus procesos, sino condición de la conciencia que la interpreta y experimenta de forma consciente o inconsciente.

Por ello, como su fenomenología y representación no pueden sino acudir a la subjetividad que lo origina, vemos en el aburrimiento un estado inmanente que trasciende su propio estigma, dando la posibilidad de disolver el juicio original para abrirlo a un campo de multi-posibilidad perceptiva más creativo. Estado anímico que Jean Carteret llamaba ennui vertical [aburrimiento vertical]: “L'ennui, c'est l'inutile qui ignore l'utile" ${ }^{3}$ [El aburrimiento, es lo inútil que ignora lo útil]. Por eso en él es posible una percepción inocente que trasciende la dialéctica del pensamiento. Como en la estrategia del perdón planteada por La Rouchefoucauld.

Actualmente, Byung-Chul Han reivindica la necesidad del aburrimiento como enemigo de la cultura contemporánea. Un aburrimiento inadvertido ya ante el exceso de positividad, uniformidad estructural y cultural, cuya hegemonía tiene para el autor la capacidad de castrar la atención consciente mediante la hiperestimulación. Así, la huida del aburrimiento es la huida de la lentitud. Adictos al frenesí de la dispersión, el multitasking vela contra el aburrimiento contemporánea. Por ello declara Han que esta emoción pudiera ser una solución que restablezca el equilibrio de la percepción, acercándola al proceso creativo original, ya que del aburrimiento parte la contemplación profunda que explicamos y que la sociedad del rendimiento anula. Un ejemplo para explicar esto es el de la danza: "Quien se aburra al caminar y no tolere el hastío deambulará inquieto y agitado, o andará detrás de una u otra actividad. Pero en cambio, quien posea una mayor tolerancia para el aburrimiento reconocerá, después de un rato, que quizás andar, como tal, lo aburre. [...] A lo mejor, puede que al andar lo invada un profundo aburrimiento, de modo que, a través de este ataque de hastío, haya pasado del paso acelerado al paso de baile. En comparación con el andar lineal y rectilíneo, la danza, con sus movimientos llenos de arabescos, es un lujo que se sustrae totalmente del principio de rendimiento." ${ }^{4}$

En definitiva, la toma de conciencia del aburrimiento como producto de nuestras propias proyecciones mentales no potencia ni anula la creatividad. Pero sí es un recurso útil que la señala, al situarnos como hacedores de nuestra percepción. Por esto permite liberarnos del caracter utilitario y productivista que suele limitar la creatividad. Pero también, como supo ver Marcel Duchamp del happening, la consciencia del aburrimiento permite ampliar nuestro campo de conciencia artística: "Los happenings han introducido en el arte un elemento que nadie había puesto: el aburrimiento. ¡Yo nunca había pensado en hacer una cosa para que la gente se aburriera viéndola! Y es una lástima, porque se trata de una buena idea." ${ }^{5}$

\section{FUENTES REFERENCIALES.}

CABANNE, P., Conversaciones con Marcel Duchamp, Barcelona, Anagrama, 1984.

CARTERET, J., "L’ennui", Kanal 5-Inédits.

ECHEVERRÍA, R., Por la senda del pensar ontológico, Granica, Buenos Aires, 2007.

HAN, B.C., La sociedad del cansancio, Herder, Barcelona, 2012.

ROCHEFOUCAULD, F., Máximas, Akal, Madrid, 1984.

\footnotetext{
${ }^{2}$ ROCHEFOUCAULD, F., Máximas, Akal, Madrid, 1984, p.64.

${ }^{3}$ CARTERET, J., "L'ennui", Kanal 5-Inédits, p.69.

${ }^{4}$ HAN, B.C., La sociedad del cansancio, Herder, Barcelona, 2012, p.36.

${ }^{5}$ CABANNE, P., Conversaciones con Marcel Duchamp, Barcelona, Anagrama, 1984, p.161.
} 